\title{
Assessment of depressive symptoms among students at Al-Kindy College of Medicine in Baghdad
}

\author{
YOSSRA KHALAF HANOON ${ }^{1, A-F}$, HUDA ADNAN HABIB ${ }^{2, ~ A-F}$
}

ORCID ID: 0000-0002-2615-1566

${ }^{1}$ Department of Family and Community Medicine, College of Medicine, Mustansiriya University, Baghdad, Iraq ${ }^{2}$ Department of Family and Community Medicine, Al-Kindy College of Medicine, Baghdad University, Iraq

A - Study Design, B - Data Collection, C - Statistical Analysis, D - Data Interpretation, E - Manuscript Preparation, F - Literature Search, G - Funds Collection

Summary Background. Depression is one of the most common medical illnesses worldwide. Medical students during their training will be subjected to many stressors, both mentally and emotionally.

Objectives. Assess the prevalence of depressive symptoms among medical students and to identify any association between depressive symptoms and some socio-demographic factors.

Material and methods. A descriptive cross-sectional study was conducted in Baghdad city, and our study sample was 800 medical students from all six stages at Al-Kindy College of Medicine. Out of those sample students, only a convenient sample of 301 students was selected, and they agreed to take part in the current study. Data was collected using a self-administered questionnaire form.

Results. The overall prevalence of depressive symptoms is $55.48 \%$ among students. The stage of the study, gender and social relationship were significantly associated with depression symptoms, with no significant association between chronic disease and monthly family income. The highest percentage of depressive symptoms was seen among students of the first, third, and fourth grade, being female, and social students with a $p$-value less than 0.05 .

Conclusions. A high level of depressive symptoms among students at Al-Kindy College of Medicine was reported, with females being more depressed than males, more than half of the participants showing symptoms and most students in the pre-clinical stage, whereas the lowest level appeared among stage six students.

Key words: depression, medical students, surveys and questionnaires.

Hanoon YK, Habib HA. Assessment of depressive symptoms among students at Al-Kindy College of Medicine in Baghdad. Fam Med Prim Care Rev 2021; 23(3): 307-312, doi: https://doi.org/10.5114/fmpcr.2021.108195.

\section{Background}

Depression is a common and serious medical illness that negatively affects how the a person feels, the way he thinks, and how he acts. It is a mood disorder that causes a persistent feeling of sadness and loss of interest and decreased energy, and it differs from normal mood changes by the severity and duration of symptoms, so it can cause various emotional, mental, and physical problems which affect the a person's abilities [1].

College students face a wide spectrum of ongoing stressors concerning educational demands. Previous studies have shown that stress can result in poor academic performance and an increase the rate of dropouts, in addition to an increase in the prevalence of mental problems, including anxiety, sleep disorders and depression [2].

Depression can lead to a variety of symptoms from mild to severe, which may vary from feeling sad or having a depressed mood with thoughts of death or suicide. To diagnose depression, symptoms must last at least two weeks. Stress could be a cause or an effect of depression, and the burden of this problem could lead to poor quality of life and may end with suicidal attempts. For these reasons, identification of risk factors of this disorder among medical students should be a priority [3].

In addition to trying to fit in, having good grades and being away from home often lead to anxiety for a large number of students, and as a result of these stressors, some will develop depression. Fearfulness of annual examinations, in a particular practical examination, causes sleep deprivation, which gives rise to depression [4].
Depression was ranked by the World Health Organization (WHO) as the fourth leading cause of disability worldwide, and it is suspected to be the second leading cause by 2020 [5].

Depression is a common illness worldwide, with more than 300 million people being affected. People with depression are frequently not diagnosed, and antidepressants are often prescribed to those who are not true cases of depression The relatively high prevalence of depression among students in medical schools has been reported in many earlier studies [6]. A majority of these have been carried out in western countries and in other parts of the world. Depression, which is self-identified among medical school students in previous studies ranged from $50 \%$ to $70 \%$, with males being less depressed than females [7]. Several studies have reported stress among medical undergraduates as between $12 \%$ to $73 \%$ and stated that the first two years of study in medical school had the highest percentages of depressive symptoms scores [8].

Depressive symptoms were more prevalent in European countries. The prevalence of depressive symptoms observed in a study conducted on university students from Eastern and Western Europe, it reported that the prevalence of depressive symptoms among the students in the Eastern European countries was $3.2 \%$, whereas it was $23.5 \%$ in the Western European countries $[9,10]$. A cross-sectional research study carried out on medical students in Egypt showed that the prevalence of depressive symptoms, stress and anxiety among students was $63.6 \%, 57.8 \%$ and $78.4 \%$, respectively [11].

A study in India on the prevalence of self-identified depression demonstrated that it was much higher in the first two years compared to the next two years. This result is compatible with earlier studies [7]. 
A cross-sectional study was conducted in Pakistan among medical college students and reported that the overall prevalence rate of depressive symptoms was $60 \%$ [8], while in Iran, The prevalence of depression among medical students was $33 \%$ [3]. In Lebanon and the UAE, the prevalence rate of depression was $34.4 \%$ and $54.4 \%$, respectively $[12,13]$.

Regarding the prevalence in Iraq, a study showed that 121 out of 271 medical students complaining of stress with a prevalence reached $44.6 \%$, and the highest percentage reported among the first-year students $(62.8 \%)$, followed by $55.6 \%$ among $5^{\text {th }}$ year students, while $6^{\text {th }}$ year students recorded the least percentage $(27.3 \%)$. The same study stated that the prevalence of stress was much higher among females than males (52.5\% vs $33.6 \%)$ [14].

The Iraqi Mental Health Survey carried out by WHO demonstrated that the prevalence of depressive symptoms was $7.2 \%$, while in an earlier study conducted in Baghdad, reported that the probable prevalence of depressive symptoms among healthcare workers was observed to be $66.5 \%$. This points to the fact that the high prevalence rate among younger doctors is not merely a part of the general unsteady situation in the country, but that there is added pressure on the people working in the medical field [13].

To prevent depression among medical students, it suggests that medical schools should provide early detection programs and interventions before graduation, and this can be done by detecting the stressful times during medical study that may have a negative psychological impact when targeted support is needed. This can encourage students to seek aid without the fear of stigmatization, and attempts should be made to alleviate the stress at the beginning of the study in medical school [15].

The objectives of the current study are to assess depressive symptoms among the medical students at AL-Kindy College of Medicine and to study the influence of some demographic factors and class level of depressive symptoms.

\section{Material and methods}

\section{Patients and methods}

A descriptive cross-sectional study was conducted in Baghdad, the capital of Iraq, at Al-Kindy College of Medicine. The data were collected from $12^{\text {th }}$ of November 2018 to $3^{\text {rd }}$ of April 2019.

This study was carried out to assess depressive symptoms among a convenient sample which included medical students at all six stages at Al-Kindy College of Medicine. Out of 800 students, only 301 students were recruited, and they agreed to participate in the study. 15 students were excluded from the study because they did not agree to participate.

\section{Inclusion criteria}

Any undergraduate student who agreed to participate, no matter their stage, age and gender. A pilot study was first conducted among 10 students chosen as follows: one student from the first, fifth and sixth stage, two students from the second and the third stage, three students from the fourth stage. The pilot study was conducted to find out if there were any unclear questions and to explore if there are other questions or aspects that may affect the students' response and which were not included in the questionnaire form.

\section{Tool of data collection}

The data were collected by using a self-administered questionnaire, which was distributed to the students who met the inclusion criteria. The questionnaire forms were distributed almost every day and collect on the same day or the day after. It was designed by the researcher after reviewing different published papers related to the problem under study. The final version of the questionnaire form consisted of two parts:

The first part consists of questions related to some socio-demographic characteristics, including age, gender, grade of the student, residence, marital status and living condition.

The second part, assessment of depressive symptoms, was done by using the Center for Epidemiological Studies Depression Scales (CESD-R), which is a well-known psychometric tool used as a standardized scale for assessment of depressive symptoms. The CESD-R scale measures depressive symptoms in nine various domains which comprise twenty items, as defined by the fifth edition of the American Psychiatric Association Diagnostic and Statistical Manual [14].

For each question, the scores ranged as follows:

- Not at all or less than one day $=0$,

- $\quad 1-2$ days = 1,

- $\quad 3-4$ days $=2$,

- $\quad$ 5-7 days and nearly every day for 2 weeks $=3$.

Scores for items $4,8,12$ and 16 are reversed before summing all items to yield a total score. The possible scores ranged between 0 (for the students who answered 'not at all or $<1$ day' to all 20 questions and 60 for students who answered ' 5 to 7 days' or 'approximately every day for 2 weeks' for all 20 questions. An overall score of $<16$ was considered normal or no depressive symptoms. A total score equal to or more than 16 to less than 23 was considered possible depression or showing some of depressive symptoms. A total score equal to or more than 23 was considered depressive.

\section{Ethical approval and permission}

Consents for participation in the study were obtained according to the Helsinki II Declaration [16]. The conduct of the study was approved by the ethical committee and the scientific research committee at Al-Kindy College of Medicine/Baghdad University. The participants were fully informed about the study purpose and significance, and verbal consent was obtained from all the participants who were recruited in the study. The confidentiality of the obtained information was considered.

\section{Statistical analysis}

Data analysis was achieved by using the statistical package of SPSS-25 (Statistical Packages for Social Sciences-version 25).

The data are shown in tables and graphs using range, mean, frequency, percentage and standard deviation. The Chi-square test was used to describe the association between related variables. $p$ was considered statistically significant whenever it was equal to or less than 0.05 .

\section{Results}

The response rate was $92 \%$, with 301 out of 326 students completing the questionnaire form. The highest percentage of participants was among the first stage students $17.3 \%$ and the lowest percentage of participation was among sixth stage students $15.9 \%$. Females constituted $65.1 \%$ of the sample, and $73.1 \%$ of the participants were living with their parents, $72.8 \%$ of them have a good family income (monthly income 1 million and more), $86 \%$ of the participants have no associated chronic disease (Table 1). 


\begin{tabular}{|c|c|c|c|}
\hline \multicolumn{2}{|l|}{ Variables } & \multirow{2}{*}{$\frac{n}{52}$} & \multirow{2}{*}{\begin{tabular}{|l|}
$\%$ \\
17.3
\end{tabular}} \\
\hline Stage & first stage & & \\
\hline & second stage & 50 & 16.6 \\
\hline & third stage & 50 & 16.6 \\
\hline & fourth stage & 50 & 16.6 \\
\hline & fifth stage & 51 & 16.9 \\
\hline & sixth stage & 48 & 15.9 \\
\hline & total & 301 & 100.0 \\
\hline \multirow[t]{3}{*}{ Gender } & male & 105 & 34.9 \\
\hline & female & 196 & 65.1 \\
\hline & total & 301 & 100.0 \\
\hline \multirow{5}{*}{$\begin{array}{l}\text { Who you are liv- } \\
\text { ing with? }\end{array}$} & with father & 6 & 2.0 \\
\hline & with mother & 16 & 5.3 \\
\hline & with parent & 220 & 73.1 \\
\hline & with relatives & 9 & 3.0 \\
\hline & dorm & 50 & 16.6 \\
\hline \multirow{3}{*}{$\begin{array}{l}\text { Monthly income } \\
\text { of the family }\end{array}$} & good (1M or more) & 219 & 72.8 \\
\hline & intermediate (500K-1M) & 74 & 24.6 \\
\hline & weak (less than 500K) & 8 & 2.7 \\
\hline \multirow{2}{*}{$\begin{array}{l}\text { Do you have } \\
\text { a chronic disease? }\end{array}$} & yes & 42 & 14.0 \\
\hline & no & 259 & 86.0 \\
\hline
\end{tabular}

Table 2 shows the prevalence of depressive symptoms, which was $55.5 \%$, and possible depressive symptoms, $32.2 \%$.

\begin{tabular}{|c|c|c|}
\hline Variables & $n$ & $\%$ \\
\hline No depressive symptoms & 37 & 12.3 \\
\hline Possible depressive symptoms & 97 & 32.2 \\
\hline Depressive symptoms & 167 & 55.5 \\
\hline Total & 301 & 100.0 \\
\hline
\end{tabular}

There is a significant association between the year of study and the prevalence of depressive symptoms $(p=0.045)$. The highest prevalence of depressive symptoms $19.2 \%$ was found among students in $1^{\text {st }}$ year of the study with least prevalence among the students of the $6^{\text {th }}$ year students as shown in Table 3.

A higher percentage of depressive symptoms appeared among female students $(73.1 \%)$ compared to males $(26.9 \%)$, and possible depressive symptoms amounted to $55.7 \%$ in females and $44.3 \%$ in males. There was also a highly significant correlation between females and the appearance of depressive symptoms $(p=0.005)$. Figure 1 and Table 4 show that there is a highly significant association between the social relations of students and depressive symptoms $(p=0.005)$. The high prevalence of depressive symptoms $59.9 \%$, and possible depressive symptoms $64.9 \%$, was found among social students.

\begin{tabular}{|c|c|c|c|c|c|c|c|}
\hline \multirow[t]{3}{*}{ Variables } & \multicolumn{6}{|c|}{ Results } & \multirow[t]{3}{*}{$p$} \\
\hline & \multicolumn{2}{|c|}{ No depressive symptoms } & \multicolumn{2}{|c|}{ Possible depressive symptoms } & \multicolumn{2}{|c|}{ Presence of depressive symptoms } & \\
\hline & $n$ & $\%$ & $n$ & $\%$ & $n$ & $\%$ & \\
\hline First stage & 7 & 18.9 & 13 & 13.4 & 32 & 19.2 & \multirow[t]{6}{*}{0.045} \\
\hline Second stage & 3 & 8.1 & 21 & 21.6 & 26 & 15.6 & \\
\hline Third stage & 3 & 8.1 & 15 & 15.5 & 32 & 19.2 & \\
\hline Fourth stage & 3 & 8.1 & 15 & 15.5 & 32 & 19.2 & \\
\hline Fifth stage & 10 & 27.0 & 15 & 15.5 & 26 & 15.6 & \\
\hline Sixth stage & 11 & 29.7 & 18 & 18.6 & 19 & 11.4 & \\
\hline
\end{tabular}

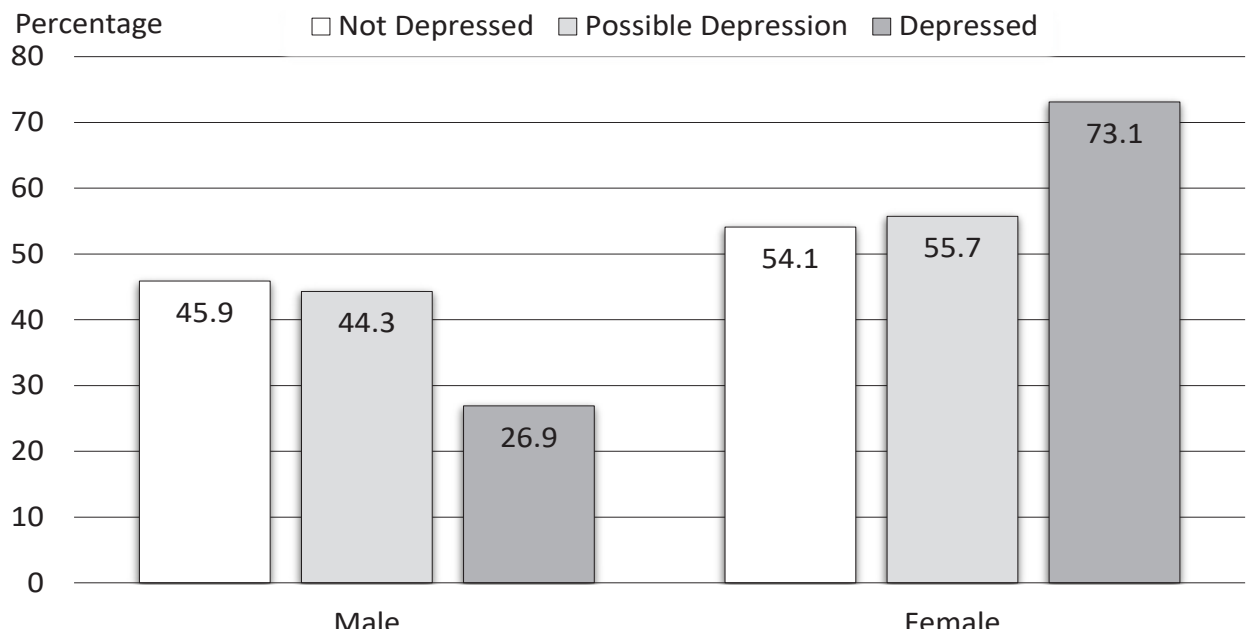

Figure 1. Association of students' gender and the depression symptoms scale assessment 


\begin{tabular}{|c|c|c|c|c|c|c|c|c|c|c|}
\hline \multirow{3}{*}{\multicolumn{2}{|c|}{ Variables }} & \multicolumn{8}{|c|}{ Results } & \multirow[t]{3}{*}{$p$} \\
\hline & & \multicolumn{2}{|c|}{ Not depressed } & \multicolumn{2}{|c|}{$\begin{array}{l}\text { Possible depres- } \\
\text { sion }\end{array}$} & \multicolumn{2}{|c|}{ Depressed } & \multicolumn{2}{|c|}{ Total } & \\
\hline & & $n$ & $\%$ & $n$ & $\%$ & $n$ & $\%$ & $n$ & $\%$ & \\
\hline \multirow{5}{*}{$\begin{array}{l}\text { Who you are living } \\
\text { with? }\end{array}$} & with father & 0 & 0.0 & 2 & 2.1 & 4 & 2.4 & 6 & 2.0 & \multirow[t]{5}{*}{0.592} \\
\hline & with mother & 1 & 2.7 & 3 & 3.1 & 12 & 7.2 & 16 & 5.3 & \\
\hline & with parents & 30 & 81.1 & 69 & 71.1 & 121 & 72.5 & 220 & 73.1 & \\
\hline & with relatives & 0 & 0.0 & 3 & 3.1 & 6 & 3.6 & 9 & 3.0 & \\
\hline & dorm & 6 & 16.2 & 20 & 20.6 & 24 & 14.4 & 50 & 16.6 & \\
\hline \multirow{3}{*}{$\begin{array}{l}\text { Monthly income of } \\
\text { the family }\end{array}$} & good (1M or more) & 30 & 81.1 & 71 & 73.2 & 118 & 70.7 & 219 & 72.8 & \multirow[t]{3}{*}{0.610} \\
\hline & intermediate $(500 \mathrm{~K}-1 \mathrm{M})$ & 7 & 18.9 & 24 & 24.7 & 43 & 25.7 & 74 & 24.6 & \\
\hline & weak (less than 500K) & 0 & 0.0 & 2 & 2.1 & 6 & 3.6 & 8 & 2.7 & \\
\hline \multirow{3}{*}{$\begin{array}{l}\text { How do you estimate } \\
\text { your social relation- } \\
\text { ship? }\end{array}$} & social & 32 & 86.5 & 63 & 64.9 & 100 & 59.9 & 195 & 64.8 & \multirow[t]{3}{*}{0.005} \\
\hline & timid & 3 & 8.1 & 27 & 27.8 & 38 & 22.8 & 68 & 22.6 & \\
\hline & secluded & 2 & 5.4 & 7 & 7.2 & 29 & 17.4 & 38 & 12.6 & \\
\hline \multirow{2}{*}{$\begin{array}{l}\text { Do you have a chron- } \\
\text { ic disease? }\end{array}$} & yes & 4 & 10.8 & 11 & 11.3 & 27 & 16.2 & 42 & 14.0 & \multirow[t]{2}{*}{0.463} \\
\hline & no & 33 & 89.2 & 86 & 88.7 & 140 & 83.8 & 259 & 86.0 & \\
\hline
\end{tabular}

\section{Percentage}

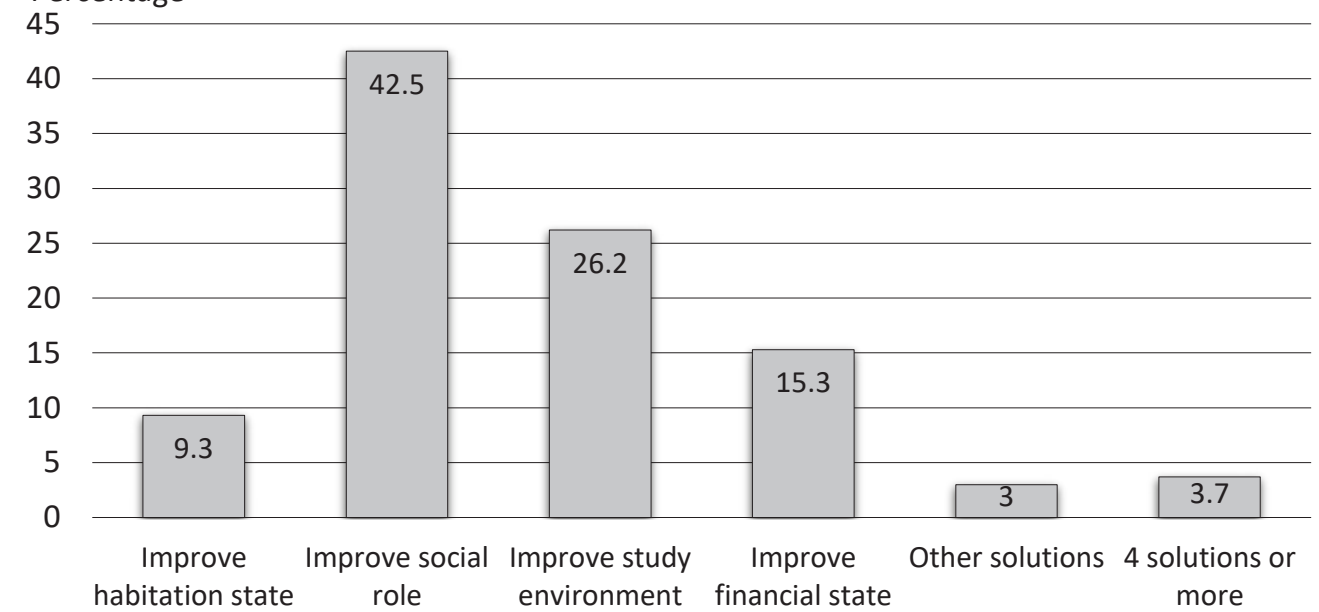

Figure 2. Distribution of sample according to students suggestions to prevent depression symptoms

Variables like the person's living status $(p=0.592)$, monthly income $(p=0.610)$ and students with chronic diseases $(p=$ 0.463 ) were not significantly associated with depressive symptoms.

Regarding the students' opinions on how to improve depressive symptoms, the current study showed that $(42.5 \%)$ of students thought improvement of the social role of a person would lead to preventing depressive symptoms. And $26.2 \%$ of the students thought that the improvement of study environment may play appositive role in the prevention of these symptoms. While only $15.3 \%$ of the sample had an opinion that the depressive symptoms may be improved by the improvement of the financial state as shown in Figure 2.

\section{Discussion}

Students in medical schools are at a greater risk of developing mental and physical health complaints as compared to non-medical students due to educational stress. Depression among students in medical schools is significantly higher. For this reason, it is essential to study the prevalence of depressive symptoms and stress among these students, as they encounter notable pressure during their years of medical education [17]. According to this study that the prevalence rate of depressive symptoms overall are more than $50 \%$ of participants. This result is contrary to a study done concerning the prevalence and predisposing factors in Cameroon, which show that the prevalence of depressive symptoms was about 30.6\% [18]. Almost the same result was found, according to a meta-analysis study about the prevalence of depressive symptoms and suicidal ideation among medical students, which included 195 studies in 47 countries and which documented that the prevalence estimates of depression or depressive symptoms reported by 183 studies yielded a crude summary prevalence of $27.2 \%$ [19]. According to the study done at Al-Azhar University, which shows that overall prevalence among medical student was $42.9 \%$ [20], but previous study done at University of Copenhagen revealed that $30.5 \%$ of medical students have depressive symptoms and stress [21], and $16.8 \%$ of students reported depressive symptoms according to a study carried out at Anhui Medical University in China [22]. In a study that conducted on medical students at Umm Al-Qura University in Makkah, Saudi Arabia, the prevalence of depressive symptoms was $30.9 \%$ [23]. Many other studies agree with the present study findings as the study done in Alexandria University which showed that more than a half of the medical 
students (57.9\%) have depressive symptoms [24]. And (49.1\%) of the students had depressive symptoms, according to a study of the Private Medical College in India [25]. Despite of this disparity in the prevalence of depression globally, different factors can be blamed for these differences. These include variations in of training programs periods, the purpose of the study, and the various scale depression assessments used in the study, as well as cultural differences around the world [20].

The present study identified that there is a significant negative association between the years of study and the appearance of depressive symptoms $(p=0.045)$. A high rate of depressive symptoms was recorded in the first, third and fourth stages (which could be considered a preclinical stage), and the lowest prevalence of symptoms was revealed among the sixth stage students. This finding was also reported by other studies which showed that the prevalence of depressive symptoms was significantly higher among the students of the first three years of medical study (basic science course) compared to students involved in their clinical training years $\left(4^{\text {th }}, 5^{\text {th }}\right.$ and $6^{\text {th }}$ years $)$, where the prevalence was $48.4 \%$ and $36.8 \%$, respectively [21]. A previous Turkish study revealed that there was a higher prevalence of depressive symptoms among second-year students [26], and another study conducted in Nepal proved that the prevalence of depressive symptoms was less among students of clinical years [27]. However, the findings of a study carried out in North America proposed that the main negative effect on mental health was seen after joining medical school and mental health remained poorly affected throughout the study years, particularly in the shift from basic science teaching to clinical training [28].

This can be explained by the high level of psychological stress in the first years of the study, as the students were unable to cope with educational demands due to their new study environment.

The present study revealed that final year students had the greatest prevalence of depressive symptoms, and this finding may be explained by increased stress and study requirements during the last year of medical study. Another study conducted in Saudi Arabia on medical students clarified that stress significantly decreased as the year of study increased, except for the sixth year [29]. This high prevalence of depressive symptoms might be due to the new experience of the students with a new study environment, the greater degree of the workload with an obligation to succeed, living far from their family, changes in the manner of their eating habits, sleep disturbance, financial responsibility and loss of leisure time in the first-year [28].

On the other hand, the third year considered an intermediate stage, and this may cause additional stress on medical students as it is the beginning of real clinical contact with patients, and transportation difficulties between hospitals may aggravate the depressive symptoms among fourth stage students. The reason that the sixth year students have a low level of depressive symptoms might be explained by acclimatization with the environment which may play a role in the reduction of the prevalence of depressive symptoms [23].

Regarding gender, the current study shows a significant association between depressive symptoms and gender $(p=0.005)$, with a high prevalence among females, which is approximately three times higher than males. This finding was also found in almost all studies. A previous study at al-Azhar University, which recruited medical students to assess the prevalence of depressive symptoms, showed that depressive symptoms were significantly more prevalent among female students (46.4\%) compared to males (39.5\%) [20].

In Alexandria, a study on medical students found that $52.5 \%$ of males and $62.2 \%$ of females were suffering from depression [24], and the incidence of depressive symptoms was found to be higher among female students (32.43\%) compared to male students $(28.07 \%)$. However, this association failed to reach a significant level $(p=0.651)$ [27].
The higher levels of depressive symptoms were reported among females, and the possible explanation for such a finding that the females are more liable to be stressed and over complaining about physical and psychological symptoms. A similar interpretation was asserted in earlier studies [23, 25].

The current study reported no significant relation between chronic diseases and depressive symptoms, as was expected, this finding was in agreement with a study conducted on medical students at Taif University, KSA [30]. But disagreed with another study that supports such a strong association between the presence of chronic disease and depressive symptoms since chronic diseases affect the quality of life and put more stress on the student in addition to the medical study difficulties [18].

Social relations and support are of the most important factors in sustaining one's physical and mental health by "buffering" the adverse effects of stress. Although medical students may experience susceptibility to psychological morbidity, many previous studies propose that social support plays a role in controlling the level of psychological symptoms [21].

The current study reported a highly significant association between social relationship and depressive symptoms, with a higher prevalence of depressive symptoms appearing among students who estimate themselves as social and the lowest prevalence among those who consider themselves as isolated. This could be explained as when a person becomes more social this will increase stress upon him to deal with different personalities, and this will increase stress especially as a person consider his/her social life as an important part of his/her life style therefore to communicate positively with those surrounded would put them under stress, while the secluded person won't deal with many people so he/she lives a quiet life without or with minimum stress compare to the social person.

No significant association between monthly income of family and depressive symptoms was revealed in the present study. The same was reported in two previous studies of the prevalence of depression among medical students at Wah Medical College in Pakistan [31] and in Syria [32]. On the contrary, a positive association was reported by many studies, which stated that depressive symptoms were about 3 times higher among students with a low income $(p=0.03)$ and about 1.5 times higher among students with a moderate socio-economic status $(p=0.044)$ than those with a high economic status. This verdict was consistent with another study of medical students in Turkey [25].

Regarding the study limitations, there were several methodological limitations due to the use of the cross-sectional design, including recall bias due to the retrospective nature of such a design, and the cross-sectional study is incompetent in establishing a causal association between the variables. Another limitation is the anonymity of the study, which did not give the researchers the opportunity to follow up with the students with depressive symptoms. The CESD-R scale failed to give an indication of clinical symptoms that were assessed, so further study is needed, and it may be worth using CESD-R item factor analysis to define the actual depressive symptoms and to distinguish them from those related to the stress of study in medical college.

\section{Conclusions}

The prevalence of depressive symptoms among medical students was high, and depressive symptoms were higher among females than males, with a significant statistical association between depressive symptoms and the female gender and class level. Thus students are in great need of support, as they are less likely to seek and receive help. Ideally, we should have a confirmed diagnosis of depression by psychiatrists, and those found to have depressive symptoms should be consoled and treated. Further studies are needed to compare the prevalence of depressive symptoms between students of medical colleges with students from other colleges. 
Source of funding: This work was funded from the authors' own resources.

Conflicts of interest: The authors declare no conflicts of interest.

\section{References}

1. Kebede MA, Anbessie B, Ayano G. Prevalence and predictors of depression and anxiety among medical students in Addis Ababa, Ethiopia. Int J Ment Health Syst 2019; 13(1): 30.

2. Amirkhan JH, Bowers GK, Logan C. Applying stress theory to higher education: lessons from a study of first-year students. Stud High Educ 2020; 45: 2231-2244.

3. Pham T, Bui L, Nguyen A, et al. The prevalence of depression and associated risk factors among medical students: an untold story in Vietnam. PLOS ONE 2019; 14(8): e0221432.

4. Sharma B, Wavare R, Deshpande A, et al. A study of academic stress and its effect on vital parameters in final year medical students at SAIMS Medical College, Indore. Biomed Res 2011; 22(3): 361-365.

5. Kessler RC, Bromet EJ. The epidemiology of depression across cultures. Annu Rev Public Health 2013; 34: 119-138.

6. Depression from WHO website (cited 30.01.2018). Available from URL: https://www.who.int/news-room/fact-sheets/detail/depression.

7. Vankar JR, Prabhakaran A, Sharma H. Depression and stigma in medical students at a private medical college. Indian J Psychol Med 2014; 36(3): 246-254.

8. Inam SB. Anxiety and depression among students of a medical college in Saudi Arabia. Int J Health Sci 2007; 1(2): 295.

9. Mikolajczyk RT, Maxwell AE, El Ansari W, et al. Prevalence of depressive symptoms in university students from Germany, Denmark, Poland and Bulgaria. Soc Psychiatry Psychiatr Epidemiol 2008; 43(2): 105-112.

10. Arslan G, Ayranci U, Unsal A, et al. Prevalence of depression, its correlates among students, and its effect on health-related quality of life in a Turkish university. Ups J Med Sci 2009; 114(3): 170-177.

11. Yeshaw Y, Mossie A. Depression, anxiety, stress, and their associated factors among Jimma University staff, Jimma, Southwest Ethiopia, 2016: a cross-sectional study. Neuropsychiatr Dis Treat 2017; 13: 2803-2812.

12. Naja WJ, Kansoun AH, Haddad RS. Prevalence of depression in medical students at the Lebanese University and exploring its correlation with Facebook relevance: a questionnaire study. JMIR Res Protoc 2016; 5(2): e96.

13. Lafta RK, Dhiaa S, Tawfeeq WA, et al. Association of violence with anxiety and depression among Iraqi Junior Doctors. Int J Appl Psychol 2016; 6(6): 163-170.

14. The Center for Epidemiologic Studies Depression Scale Revised (CESD-R) (cited 24.03.2018). Available from URL: http://cesd-r.com/ about-cesdr/.htm.

15. Thiemann P, Brimicombe J, Benson J, et al. When investigating depression and anxiety in undergraduate medical students timing of assessment is an important factor - a multicentre cross-sectional study. BMC Med Educ 2020; 20: 1-8.

16. World Medical Association. Declaration of Helsinki. Ethical principles for medical research involving human subjects. Available from URL: http://www.wma.net/e/policy/b3.htm.2008.

17. Rotenstein LS, Ramos MA, Torre M. Prevalence of depression, depressive symptoms, and suicidal ideation among medical students. JAMA 2016; 316(21): 2214-2236.

18. Ngasa SN, Sama CB, Dzekem BS, et al. Prevalence and factors associated with depression among medical students in Cameroon: a cross-sectional study. BMC Psychiatry 2017; 17(1): 216.

19. Puthran R, Zhang MW, Tam WW, et al. Prevalence of depression amongst medical students: a meta-analysis. Med Educ 2016; 50(4): 456-468.

20. Abdelwahed Shams-Eldin A, Hassan H, Amer S, et al. Prevalence of depression among medical students at AL-Azhar University: a cross sectional study. Al-Azhar Med J 2019; 48(1): 89-99.

21. Haldorsen $\mathrm{H}$, Bak NH, Dissing A, et al. Stress and symptoms of depression among medical students at the University of Copenhagen. SJPHAJ 2014; 42(1): 89-95.

22. Sun L, Sun LN, Sun YH, et al. Correlations between psychological symptoms and social relationships among medical undergraduates in Anhui Province of China. Int J Psychiatr Med 2011; 42(1): 29-47.

23. Jarwan BK. Depression among medical students of Faculty of Medicine, Umm Al-Qura University in Makkah, Saudi Arabia. Int J Med Sci Public Health 2015; 4(2): 184-191.

24. Ibrahim MB, Abdelreheem MH. Prevalence of anxiety and depression among medical and pharmaceutical students in Alexandria University. Alexandria J Med 2015; 51(2): 167-173.

25. Singh A, Lal A, Singh S. Prevalence of depression among medical students of a private medical college in India. Online J Health Allied Sci 2011; 9(4): 1-3.

26. Ediz B, Ozcakir A, Bilgel N. Depression and anxiety among medical students: examining scores of the beck depression and anxiety inventory and the depression anxiety and stress scale with student characteristics. Cogent Psychology 2017; 4(1), doi: 10.1080/23311908.2017.1283829.

27. Basnet B, Jaiswal M, Adhikari B, et al. Depression among undergraduate medical students. Kathmandu Univ Med J 2012; 10(39): 56-59.

28. Mayer FB, Santos IS, Silveira PS, et al. Factors associated to depression and anxiety in medical students: a multicenter study. BMC Med Educ 2016; 16(1): 282.

29. Ibrahim N, Dania AK, Lamis EK, et al. Prevalence and predictors of anxiety and depression among female medical students in King Abdulaziz University, Jeddah, Saudi Arabia. Iran J Public Health 2013; 42(7): 726.

30. Grohol JM. Warning Signs \& Types of Depression (cited 24.03.2018). Available from URL: https://psychcentral.com/lib/types-andsymptoms-of-depression/.htm.

31. Alvi T, Assad F, Ramzan M, et al. Depression, anxiety and their associated factors among medical students. J Coll Physicians Surg Pak 2010; 20(2): 122-126.

32. Al Saadi T, Addeen SZ, Turk T, et al. Psychological distress among medical students in conflicts: a cross-sectional study from Syria. $B M C$ Med Educ 2017; 17(1): 173.

Tables: 4

Figures: 2

References: 32

Received: 17.10 .2020

Reviewed: 15.12 .2020

Accepted: 25.04.2021
Address for correspondence:

Yossra Khalaf Hanoon, MD, PhD

Family and Community Medicine Department, College of Medicine Mustansiriyah University

Baghdad, Iraq

Tel.: +964 7827099196

E-mail: yossraalrobaiaay@gmail.com 